\title{
Chlamydia trachomatis as a cause of acute perihepatitis associated with pelvic inflammatory disease
}

\author{
K DALAKER, * H GJ $\varnothing$ NNAESS, ${ }^{*}$ G KVILE, ${ }^{*}$ A URNES, ${ }^{*}$ G ANESTAD, $†$ AND \\ T BERGAN‡
}

From the Departments of *Obstetrics and Gynaecology and $¥$ Microbiology, Aker Hospital, and the †Department of Virology, National Institute of Public Health, Oslo, Norway

SUMMARY Of four cases of acute salpingitis and perihepatitis confirmed by laparoscopy Chlamydia trachomatis was cultured from the cervix only in two and from both the cervix uteri and the Fallopian tubes in two; the latter finding has not been reported from cases with combined salpingitis and perihepatitis (Fitz-Hugh-Curtis syndrome). Since gonococci, other aerobic, or anaerobic bacteria were not isolated from the Fallopian tubes, an aetiological relationship between $C$ trachomatis and the Fitz-Hugh-Curtis syndrome is suggested.

\section{Introduction}

Acute perihepatitis is a localised fibrinous inflammation affecting the upper anterior surface of the liver and adjacent parietal peritoneum. The sequelae are fibrous adhesions between the liver and the diaphragm. The condition frequently occurs in young sexually active women and is usually associated with acute pelvic inflammatory disease (PID)-the Fitz-Hugh-Curtis syndrome (FHC)although the symptoms of salpingitis are often moderate or even absent.

The clinical picture is often characterised by an acute onset of severe right upper-quadrant abdominal pain, resembling that of acute cholecystitis. Pain may be absent in perihepatitis, which may be diagnosed accidentally during laparoscopy.

The syndrome was first described in 1919 by Stajano. ${ }^{1}$ In 1930 Curtis, ${ }^{2}$ and four years later FitzHugh, ${ }^{3}$ related the syndrome to gonococcal infection. In PID, however, it is becoming increasingly clear that gonococci are only one of several important aetiological agents. ${ }^{4}$ Among these, Chlamydia trachomatis is of increasing importance, ${ }^{5}$ and serological evidence of chlamydial infection as a possible cause of perihepatitis and peritonitis have been reported. ${ }^{6}$ Recently, $C$ trachomatis has been

Address for reprints: Dr K Dalaker, Department of Obstetrics and Gynaecology, Aker Hospital, Oslo, Norway

Accepted for publication 9 June 1980 cultured from the cervix of two patients with combined nongonococcal salpingitis and perihepatitis. $^{7}$

This report concerns four patients with the FHC syndrome. $C$ trachomatis was isolated from the cervix in all and from the Fallopian tubes in two of them.

\section{Patients and methods}

\section{DIAGNOSIS}

Four women aged 18-20 years were admitted to hospital because of right upper-quadrant abdominal pain of 1-2 weeks' duration (table). Three of them also had lower abdominal pain and were suspected of having PID. The clinical examination of the pelvis indicated salpingitis in cases 1,2 , and 3. Diagnostic laparoscopy showed perihepatitis associated with PID-the FHC syndrome-in all four patients. The tubal inflammation was graded according to Weström. ${ }^{8}$

\section{CULTURE TECHNIQUE}

Specimens for isolation of $C$ trachomatis were obtained from the cervical canal and from the fimbriae of the Fallopian tubes with a sterile cottontipped swab (Medical Wire and Equipment $\mathrm{Co}$, Corsham, Wiltshire). Specimens were placed in a plastic capsule containing $1 \mathrm{ml} 0.2 \mathrm{~mol}$ sucrosephosphate (2-SP) medium ${ }^{9}$ and then transported at $4^{\circ} \mathrm{C}$ in a thermo-container. 
TABLE Clinical findings in four women with the Fitz-Hugh-Curtis syndrome

\begin{tabular}{|c|c|c|c|c|c|c|c|c|}
\hline Case & $\begin{array}{l}\text { Earlier } \\
\text { episodes of } \\
\text { salpingitis }\end{array}$ & Contraception & $\begin{array}{l}\text { Duration of } \\
\text { symptoms before } \\
\text { admission (days) }\end{array}$ & $\begin{array}{l}\text { Tentative } \\
\text { diagnosis } \\
\text { on admission }\end{array}$ & $\begin{array}{l}\text { White blood } \\
\text { cell count } \\
\left(\times 10^{9 / 1)}\right.\end{array}$ & $E S R^{*}$ & $\begin{array}{l}\text { Rectal } \\
\text { temperature on } \\
\text { admission }\left(C^{\circ}\right)\end{array}$ & $\begin{array}{l}\text { Tubal } \\
\text { inflammatory } \\
\text { changes }\end{array}$ \\
\hline 1 & 0 & $\begin{array}{l}\text { IUD inserted } \\
3 \text { weeks earlier }\end{array}$ & 7 & $\begin{array}{l}\text { Appendicitis? } \\
\text { Salpingitis? }\end{array}$ & $10 \cdot 2$ & 81 & $39 \cdot 0$ & Moderate \\
\hline 2 & 0 & Oral contraceptive & 14 & Cholecystitis & $6 \cdot 8$ & 65 & $38 \cdot 2$ & Severe \\
\hline 3 & 1 & None & 10 & Salpingitis & $8 \cdot 3$ & 36 & $37 \cdot 2$ & Moderate \\
\hline 4 & 0 & None & 14 & Cholecystitis & $11 \cdot 1$ & 20 & $38 \cdot 0$ & Mild \\
\hline
\end{tabular}

*Erythrocyte sedimentation rate ( $\mathrm{mm}$ in first hour)

Cycloheximide-treated McCoy cell cultures were inoculated by the method of Ripa and Mårdh ${ }^{10}$ within 24 hours of collection. The cell cultures were incubated at $37^{\circ} \mathrm{C}$ for $48-72$ hours and stained by Giemsa. The cell monolayers were screened by darkground microscopy at $\times 100$ magnification; findings were subsequently confirmed at $\times 400$ magnification.

Specimens for anaerobic cultures were aspirated from the cul-de-sac, and routine cultures for Neisseria gonorrhoeae were performed with specimens from the cervical canal and the urethra. The former were transported in the syringe used for aspiration and arrived at the department of microbiology within 20 minutes for immediate processing. The bacteriological techniques for isolation and identification of anaerobes were those described. ${ }^{11}$ For isolation of gonococci laked haemolysed blood agar was used with a multivitamin supplement and with colistin, lincomycin, neomycin, and trimethoprim as selective additives. ${ }^{12}$. The plates were incubated in a humidified atmosphere enriched with $8 \% \mathrm{CO}_{2}$

\section{Results}

C trachomatis was isolated from the cervical canal of all four patients, regardless of the degree of PID, and from the Fallopian tubes in cases 2 and 4.

In all the patients the liver surface displayed fibrinous plaques and minute haemorrhagic spots. In one patient (case 1) typical violin string-like adhesions were found between the liver capsule and the parietal peritoneum.

The degree of the tubal inflammatory changes are shown in the table.

None of the cultures gave positive results for $N$ gonorrhoeae or for anaerobic or aerobic bacteria.

The patients were treated with lymecycline $300 \mathrm{mg}$ twice daily for 12-14 days. All responded satisfactorily.

\section{Discussion}

In the first reports of the FHC syndrome s.-3 $^{1-3}$ perihepatitis was observed only in patients with gonococcal salpingitis; $N$ gonorrhoeae was therefore $\overrightarrow{\vec{\omega}}$ considered to be the aetiological agent. Later, PID associated with perihepatitis was observed without $\stackrel{\text { f }}{=}$ evidence of gonococcal infection. From Norway, $y$ Onsrud $^{13}$ reported 24 unselected cases with laparoscopically confirmed FHC syndrome in which $\nexists$ cervical cultures gave consistently negative results for 0 gonococci. Huseb $\varnothing$ et $a l^{14}$ have isolated gonococci from the cervical canal of only two of 12 patients 7 with the same syndrome.

$C$ trachomatis as a possible cause of perihepatitis was first reported by Müller-Schoop et al. ${ }^{6}$ They found serological evidence of a recent chlamydial $\vec{\oplus}$ infection in nine of 11 patients with both $ळ$ perihepatitis and peritonitis. $C$ trachomatis, as an aetiological agent of the FHC syndrome, has later been suggested by $\mathrm{W} \varnothing \mathrm{lner-Hanssen}$ et $a l,{ }^{7}$ but they never isolated the micro-organism from the Fallopian tubes and in only two cases from the cervix.

At present the significance of $C$ trachomatis within $\stackrel{\varnothing}{\varnothing}$ the cervical canal is not completely clear. It may be $\overrightarrow{\overrightarrow{0}}$ isolated from the cervix without occurring con- 3 comitantly in the Fallopian tubes. In addition, $C$ 尹 trachomatis has been repeatedly found in the cervix of many apparently healthy women. ${ }^{15}$ However, the of analogy between chlamydial infections and gonorrhoea would seem to be pertinent. When gonococci 3 . have been isolated from the cervix PID has been con- $\hat{\circ}$ sidered to be of gonococcal origin. In cases of PID without gonococci or anaerobic bacteria but with $C_{0}$ trachomatis, it would accordingly seem logical to record these cases as being chlamydial in origin. This $\frac{7}{0}$ view is corroborated by the cultural demonstration of $C$ trachomatis in the cervix in $35 \%$ of cases with PID ${ }^{5}$ o and by repeated reports of significant increases in $\mathrm{N}$ antichlamydial antibody titres in cases of PID. ${ }^{16}$ N

The presence of $C$ trachomatis within the ${ }_{\sigma}^{\omega}$ Fallopian tubes in cases of PID associated with perihepatitis appears not to have been reported. As none of the microbial species ordinarily responsible for PID could be found, $C$ trachomatis must be considered to be the cause of PID in these cases and therefore also of the FHC syndrome.

Consequently, $C$ trachomatis is a possible $\frac{\stackrel{\rho}{\oplus}}{\Phi}$ aetiological agent in a number of cases of the FHC $\cong$ 
syndrome. This hypothesis is substantiated by the general finding that gonococci have never been cultured from the liver surface and only rarely from within the Fallopian tubes. If our hypothesis is correct, it may only be a matter of time before isolates of $C$ trachomatis are reported from the hepatic region.

\section{References}

1. Stajano C. La reacción frenica en ginecologica. Semana Med Buenos Aires 1920;27:243-8.

2. Curtis AH. A cause of adhesions in the right upper quadrant. JAMA 1930;94:1221-2.

3. Fitz-Hugh T. Acute gonococcic peritonitis of the right upper quadrant. JAMA 1934;102:2094-6.

4. Gjonnaess $H$. Doxycycline in pelvic inflammatory disease. Curr Ther Res 1979;26: 745.

5. Mårdh PA, Ripa KT, Svensson L, Weström L. Chlamydia trachomatis infection in patients with acute salpingitis. NEngl J Med 1977;296: 1377-9.

6. Müller-Schoop JW, Wang SP, Munzinger J, et al. Chlamydia trachomatis as possible cause of peritonitis and perihepatitis in young women. $\mathrm{Br}$ Med J 1978;1:1022-4.
7. Wølner-Hanssen $\mathbf{P}$, Weström L, Mărdh P-A. Perihepatitis in chlamydial salpingitis. Lancet 1980; i:901-4.

8. Weström L. Diagnosis, Aetiology and Prognosis of Acute Salpingitis. Studentlitteratur $A B$, Lund, Sweden, 1976: 16-17.

9. Gordon FB, Harper IA, Quan AL, et al. Detection of Chlamydia (Bedsonia) in certain infections of man. I Laboratory procedures: comparison of yolk sac and cell culture for detection and isolation. $J$ Infect Dis 1969; 120:451-62.

10. Ripa KT, Mårdh P-A. A new simplified culture technique for Chlamydia trachomatis. In: Hobson D, Holmes KK, eds. Nongonococcal Urethritis and Related Infections. Washington DC: American Society for Microbiology, 1977:323-7.

11. Bergan T, Dobloug I, Liavàg I. Bacterial isolates in cholecystitis and cholelithiasis. Scand $J$ Gastroenterol 1979; 14:625-31.

12. Ødegaard K, Solberg O, Lind J, et al. Lincomycin in selective medium for the isolation of Neisseria gonorrhoeae. Acta Pathol Microbiol Scand (B) 1975;83:301-4.

13. Onsrud M. Perihepatitt ved salpingitt. J Nor Med Assoc 1979; 33: 1705-6.

14. Huseb $\phi$ OS, Bjerkeseth T, Kalager T. Acute perihepatitis. Acta Chir Scand 1979;145:483-5.

15. Rees E, Tait IA, Hobson D, et al. Chlamydia in relation to cervical infection and pelvic inflammatory disease. In: Hobson D, Holmes KK, eds. Non-gonococcal Urethritis and Related Infections. Washington DC: American Society for Microbiology, 1977:67-76.

16. Treharne JD, Ripa KT, Mårdh P-A, et al. Antibodies to Chlamydia trachomatis in acute salpingitis. Br J Vener Dis 1978;54: 1022-4. 